\title{
COMPARISON BETWEEN INTRACORONARY VERSUS INTRAVENOUS BOLUS INJECTION OF TIROFIBAN ON INFARCT SIZE DURING PRIMARY PERCUTANEOUS CORONARY INTERVENTION IN PATIENTS WITH ACUTE ANTERIOR ST SEGMENT ELEVATION MYOCARDIAL INFARCTION
}

By

\author{
Ehab El-Hefny, Ibrahim Yassen and Mahmoud M. Osman \\ Department of Cardiology, Faculty of Medicine, Al-Azhar University \\ E-mail: $\underline{\text { mmomm@live.co.uk }}$
}

\begin{abstract}
Background: The latest guidelines considered glycoprotein IIb/IIIa inhibitors (GPI) as a bailout strategy in selected situations in patients presented with acute ST $\neg$ segment elevation myocardial infarction (STEMI), however, they did not recommend route of administration over another, and did not correlate it to infarct size. Infarct size correlates generally with prognosis following acute myocardial infarction and reduction in infarct size can boost clinical outcomes and decrease rate of heart failure hospitalization.
\end{abstract}

Objective: To evaluate intracoronary vs intravenous use of tirofiban on reduction of infarct size in STEMI treated with primary percutaneous coronary intervention (PCI).

Patients and methods: Between February, 2018, and October, 2019, one hundred patients presented within 6 hours of anterior STEMI undergoing primary PCI after exclusion of rescue PCI, thrombolysis in myocardial infarction (TIMI) flow less than II post PCI, previous myocardial infarction (MI), stent thrombosis, previous coronary artery bypass graft, significant left main occlusion, pulmonary edema and cardiogenic shock.

Infarct size was assessed 1 month after randomization by single photon emission computed tomography (SPECT) and Major adverse cardiovascular events (MACE) during hospital stay (cardiac death, myocardial infarction or stroke), heart failure and bleeding.

Results: Patients randomized to intracoronary tirofiban compared with intravenous tirofiban had a significant decrease in the primary end point of infarct size (mean \pm SD, $14.46 \% \pm 7.79 \%$ vs $18.06 \% \pm 7.83 \%$ ). Also associated with lower incidence of heart failure (16\% vs $34 \%$ ). There were no significant differences in any of the MACE or bleeding between the randomized groups at 30 days.

Conclusions: In patients with anterior STEMI presenting early after symptom onset, intracoronary tirofiban administration when compared to intravenous route during primary PCI resulted in infarction size reduction and lower heart failure incidence mainly driven by enhanced left ventricular systolic function however, no distinction between two strategies on MACE or bleeding risk.

Keywords: Infarct size, SPECT, Myocardial infarction, Tirofiban, Heart failure. 


\section{INTRODUCTION}

Tirofiban is a small molecule, nonpeptide tyrosine derivative which belongs to the class of glycoprotein IIb/IIIa inhibitors (GPIs). By preventing the binding of fibrinogen and von Willebrand factor to the GP IIb/IIIa receptor on the surface of the platelet, GPIs are currently regarded as the most potent inhibitors of platelet aggregation (Casserly and David, 2010).

Even more importantly, different dosing regimens of tirofiban have been developed over time based on the clinical setting and the timing of percutaneous coronary intervention (PCI) which has resulted in mixed results in clinical trials when compared with either placebo or abciximab (Marco and Tebaldi, 2010).

Percutaneous

coronary intervention has become the most effective treatment for acute coronary syndrome (ACS). However, a large proportion of patients present with a persistent impairment of microcirculation, which results in the no reflow phenomenon, a serious complication leading to poor prognosis (Gellatly et al., 2020).

Glycoprotein IIb/IIIa inhibitors have been widely used to guard against no-reflow (Wang et al., 2012). Several meta-analyses have demonstrated that intracoronary (IC) administration of GPIs improves clinical outcomes compared with intravenous (IV) administration (Bernardo et al., 2014).
Intravenous GPIs provide rapid and nearly complete platelet aggregation inhibition, the ability to disaggregate existing thrombus, as well as a reduction in periprocedural adverse events associated with PCI (Wilmer, 2018).

Intracoronary administration of
tirofiban may offer certain advantages. IC delivery may lead to a higher local concentration of antiplatelet agent at the level of the obstructing thrombus in the coronary artery, this may lead to higher receptor occupancy and therefore disrupting platelet crosslinking and augmenting thrombus resolution to a greater extent (Zeymer et al., 2014).

The pre-hospital routine use of glycoprotein (GP) IIb/IIIa inhibitors before primary PCI has not been demonstrated to offer a benefit and increases bleeding risk compared with routine use in the catheterization laboratory. Overall, there is no evidence to recommend the routine use of GP IIb/IIIa inhibitors for primary percutaneous coronary intervention (PPCI). At the present time there is no class I indication in European Society of Cardiology (ESC) guidelines for their use. In ST elevation myocardial infarction (STEMI) patients ESC guidelines recommend its use as bailout therapy if there is angiographic evidence of massive thrombus, slow or no-reflow or a thrombotic complication (IIa) and high-risk patients undergoing transfer for primary PCI (IIb) (Ibanez et al., 2018). 
In STEMI, the American College of Cardiology/ American Heart Association (ACC/AHA) guidelines recommend the use of GPIIb/IIIa receptor inhibitors at the time of primary PCI in the pre-catheterization laboratory setting (e.g. ambulance, emergency department) to patients with STEMI for whom primary PCI is intended (IIb). They are not recommended if PCI is not intended (III) (Levine et al., 2016).

The present work aimed to evaluate intracoronary vs intravenous use of tirofiban on reduction of infarct size in STEMI treated with primary PCI.

\section{PATIENTS AND METHODS}

This prospective randomized study was conducted between February, 2018, and October, 2019. One hundred patients presented with anterior STEMI to Cardiology Department in Al- Hussein University Hospital and National Heart Institute, and treated with primary PCI, and had indication to use glycoprotein IIB/IIIA (tirofiban).

\section{Inclusion Criteria:}

Patients were eligible for enrollment in the study if they presented within 6 hours of onset of anterior STEMI defined as at least chest pain episode lasting at least 20 minutes, demonstrated acute anterior STEMI on their qualifying ECG $(\geq 0.2 \mathrm{mV}$ in $\geq 2$ contiguous precordial leads or new pathological Q waves) on surface ECG on admission and underwent PPCI.

\section{Exclusion Criteria:}

Patients underwent rescue PCI, patients who had previous MI, patients presented with stent thrombosis, cardiogenic shock at presentation (systolic blood pressure $<80 \mathrm{~mm} \mathrm{Hg}$, unresponsive to fluids, or necessitating catecholamines), electrical instability, severe congestive heart failure, inability to provide written informed consent for participation, renal impairment and previous coronary artery bypass graft (CABG).

All eligible anterior STEMI patients (one hundred) underwent PPCI was classified into two equal groups: Group (1): Intracoronary group treated by intracoronary bolus infusion of tirofiban followed by IV maintenance dose infusion of tirofiban, and Group (2): Intravenous group treated by intravenous bolus infusion of tirofiban followed by IV maintenance dose infusion of tirofiban.

Infarct size was assessed within 3 months after randomization by single photon emission computed tomography myocardial perfusion imaging (SPECTMPI). Major adverse cardiovascular events (MACE) (cardiac death, MI or stroke), heart failure and bleeding during hospital stay and after 30 days.

\section{Statistical analysis:}

The collected data were revised, coded, tabulated and computed by using Statistical package for the Social Sciences (SPSS) version 23.0 for windows (SPSS Inc., Chicago, IL, USA). Data was presented and suitable analysis was done according to the type of data obtained for each parameter. Descriptive statistics; Mean and Standard deviation $( \pm$ SD) for numerical data, percentage of nonnumerical data. Unpaired Student t test was used to compare continuous variables between 2 independent groups, ensuring first that the data was approximately 
normally distributed for the unadjusted analysis. Non-parametric Mann-Whitney U-test was used to compare the differences in infarct size and cardiac biomarkers between groups which was not normally distributed. Linear regression was used for comparing left ventricular ejection in relation to infarct size. For all analyses, a value of $p \leq 0.05$ was considered as statistically significant.

\section{RESULTS}

Baseline characteristics of included patients were well balanced as regards coronary artery disease (CAD) risk factors and demographics with a male predominance which representing (84\%) in IC group and (78\%) in IV group. There was no statistical difference between blood pressure measurement or heart rate between both groups, and after exclusion of patients presented with Killip III or IV there, a higher incidence of Killip class II was found in IV group $40 \%$ vs $32 \%$ in IC group but statistically non-significant $\mathrm{P}$ value $=0.23$. According to time from onset of chest pain to first medical contact there was no significant statistical difference between both groups (IC group $3.14 \pm 1.3$ hours and $2.8 \pm 1.4$ hours in IV group with $P$ value $=0.205$ using Mann-Whitney U-test) (Table 1).

Table (1): Characteristics of the studied groups

\begin{tabular}{|c|c|c|c|c|}
\hline Parameters & Groups & $\begin{array}{c}\text { IC group } \\
(n=50)\end{array}$ & $\begin{array}{c}\text { IV group } \\
(n=50)\end{array}$ & $P$ value \\
\hline \multicolumn{2}{|c|}{$\begin{array}{c}\text { Age (years) } \\
\text { Mean } \pm(\mathrm{SD})\end{array}$} & $61 \pm 7.8$ & $59 \pm 6.4$ & 0.16 \\
\hline \multirow{2}{*}{$\begin{array}{c}\text { Gender } \\
\mathrm{N}(\%)\end{array}$} & Male & $42(84 \%)$ & $39(78 \%)$ & \multirow{2}{*}{0.45} \\
\hline & Female & $8(16 \%)$ & $11(22 \%)$ & \\
\hline \multicolumn{2}{|l|}{$\begin{array}{c}\mathbf{D M} \\
\mathrm{N}(\%)\end{array}$} & $36(72 \%)$ & $40(80 \%)$ & 0.35 \\
\hline \multicolumn{2}{|c|}{$\begin{array}{c}\text { Hypertensive } \\
\text { N (\%) }\end{array}$} & $35(70 \%)$ & $38(76 \%)$ & 0.5 \\
\hline \multicolumn{2}{|c|}{$\begin{array}{c}\text { Smoker } \\
\mathrm{N}(\%)\end{array}$} & $36(72 \%)$ & $39(78 \%)$ & 0.5 \\
\hline \multicolumn{2}{|c|}{$\begin{array}{c}\text { Dyslipidemia } \\
\mathrm{N}(\%)\end{array}$} & $12(24 \%)$ & $15(30 \%)$ & 0.5 \\
\hline \multicolumn{2}{|c|}{$\begin{array}{c}\text { Family history of CAD } \\
\mathrm{N}(\%)\end{array}$} & $7(14 \%)$ & $9(18 \%)$ & 0.58 \\
\hline \multicolumn{2}{|c|}{ SBP (mmHg) } & $131.8 \pm 13.2$ & $136 \pm 13.3$ & 0.12 \\
\hline \multicolumn{2}{|c|}{ DBP (mmHg) } & $82 \pm 8.5$ & $85 \pm 8.2$ & 0.08 \\
\hline \multicolumn{2}{|c|}{ Heart rate } & $92 \pm 15.7$ & $87 \pm 15.3$ & 0.11 \\
\hline \multicolumn{2}{|c|}{ Onset of chest pain } & $3.14 \pm 1.3$ & $2.8 \pm 1.4$ & $0.205(\mathrm{M}-\mathrm{W}$ test $)$ \\
\hline \multirow{2}{*}{ Killip class N (\%) } & I & $34(68 \%)$ & $30(60 \%)$ & \multirow{2}{*}{0.41} \\
\hline & II & $16(32 \%)$ & $20(40 \%)$ & \\
\hline
\end{tabular}

IC group= intracoronary group, IV group= Intravenous group, $\mathrm{SD}=\mathrm{Standard}$ deviation, $\mathrm{N}=\mathrm{Number}, \mathrm{P}$ value=Probability value, $\mathrm{DM}=$ diabetes mellitus, $\mathrm{CAD}=$ coronary artery disease. $\mathrm{SBP}=$ Systolic blood pressure, $\mathrm{DBP}=$ Diastolic blood pressure, $\mathrm{mmHg}=$ millimeter of mercury, $\mathrm{M}-\mathrm{W}$ test= Mann-Whitney U-test. 
Anterior STEMI caused by total occlusion of proximal LAD was predominant in both groups $76 \%$ in intracoronary group and $70 \%$ in intravenous group which was statistically non-significant between both groups with $(\mathrm{P}$ value $=0.49)$. The thrombus burden can be classified according to the thrombolysis in myocardial infarction (TIMI) thrombus grade (TG), According to this classification TIMI TG 4 or 5 is defined as large thrombus burden which was found in $84 \%$ of cases in intracoronary group and $82 \%$ of the cases in intravenous group without statistical difference between both groups $(\mathrm{P}$ value $=$ 0.78). There was no statistical difference in other procedural data as time to wire crossing or stent number or stent length. Discharge medications included Aspirin, clopidogrel, statin, beta blockers and Angiotensin converting enzyme inhibitors in $100 \%$ of patients with no difference between the 2 groups (Table 2).

Table (2): Procedural data of the studied groups

\begin{tabular}{|c|c|c|c|}
\hline $\begin{array}{ll}\text { Parameters } & \text { Groups } \\
\end{array}$ & $\begin{array}{c}\text { IC group } \\
(\mathbf{n}=50)\end{array}$ & $\begin{array}{c}\text { IV group } \\
(\mathbf{n}=50)\end{array}$ & $P$ value \\
\hline Proximal LAD N (\%) & $38(76 \%)$ & $35(70 \%)$ & \multirow{2}{*}{0.49} \\
\hline Mid LAD N (\%) & $12(24 \%)$ & $15(30 \%)$ & \\
\hline Thrombus grade III N (\%) & $8(16 \%)$ & $9(18 \%)$ & \multirow{2}{*}{0.78} \\
\hline Thrombus grade (IV-V) N (\%) & $42(84 \%)$ & $41(82 \%)$ & \\
\hline Direct stenting N (\%) & $46(92 \%)$ & $44(88 \%)$ & \multirow{2}{*}{0.5} \\
\hline PTCA + stenting N (\%) & $4(8 \%)$ & $6(12 \%)$ & \\
\hline DES N (\%) & $50(100 \%)$ & $50(100 \%)$ & 1 \\
\hline
\end{tabular}

IC group= Intracoronary group, IV group $=$ Intravenous group, $\mathrm{N}=$ Number, $\%=$ Percentage, $\mathrm{P}$ value $=$ Probability value, $\mathrm{NS}=$ Non-significant, $\mathrm{SD}=\mathrm{Standard}$ deviation, $\mathrm{LAD}=$ Left anterior descending artery, PTCA= Percutaneous transluminal coronary intervention, DES= Drug eluting stent, mm=Millimeter.

Myocardial blush grade (MBG) of 2 or 3 , were achieved in $100 \%$ of patients of both groups. Complete ST segment resolution (STR) at 60 minutes post PPCI were achieved in $100 \%$ of patients of both groups and after exclusion of cases postPCI with TIMI Flow less than II, Post-PCI TIMI 3 flow could be achieved in $92 \%$ of cases in IC group and $88 \%$ of cases in IV group but this difference is statistically non-significant $(\mathrm{P}=0.5)$. Left ventricular systolic function which presented as ejection fraction (EF) was higher in IC group $45.64 \pm 6.98$ VS $43.44 \pm 6.15$ in IV group but statistically non-significant $(\mathrm{P}=$
0.09). Peak CK-MB (creatine kinase myocardial band) was higher in IV group $127.4 \pm 65.44$ VS $107.9 \pm 48.94$ in IC group but statistically non-significant $(\mathrm{P}=$ 0.15 using Mann-Whitney U-test). Infarct size was assessed 1 month after randomization by single photon emission computed tomography myocardial perfusion imaging (SPECT-MPI). There were a higher percentage of infarct size among IV group $18.06 \pm 7.83 \mathrm{VS} 14.46 \pm$ 7.79 in IC group and the differences between both study groups was statistically significant $(\mathrm{P}=0.018$ using Mann-Whitney U-test) (Table 3). 
Table (3): Measures of myocardial perfusion

\begin{tabular}{|l|l|c|c|c|}
\hline \multicolumn{2}{|c|}{ Groups } & \multicolumn{1}{|c|}{$\begin{array}{c}\text { IC group } \\
\text { Parameters }\end{array}$} & $\begin{array}{c}\text { IV group } \\
(\mathbf{n = 5 0})\end{array}$ & P value \\
\hline STR & $50(100 \%)$ & $50(100 \%)$ & 1 \\
\hline \multirow{2}{*}{ TIMI flow } & II & $4(8 \%)$ & $6(12 \%)$ & 0.5 \\
\cline { 2 - 4 } MBG 2 or 3 & $46(92 \%)$ & $44(88 \%)$ & 1 \\
\hline ECHO (EF\%) & $50(100 \%)$ & $50(100 \%)$ & 0.09 \\
\hline $\begin{array}{l}\text { Peak CK-MB (IU/L) } \\
\text { (mean } \pm \text { SD) }\end{array}$ & $45.64 \pm 6.98$ & $43.44 \pm 6.15$ & $\begin{array}{c}0.15 \\
(\mathrm{M}-\mathrm{W} \text { test })\end{array}$ \\
\cline { 1 - 3 } Infarct size (mean \pm SD) & $107.9 \pm 48.94$ & $127.4 \pm 65.44$ & $\begin{array}{c}0.018 \\
(\text { M-W test })\end{array}$ \\
\hline
\end{tabular}

IC group= Intracoronary group, IV group= Intravenous group, \%= Percentage, $\mathrm{P}$ value=Probability value, $\mathrm{NS}=$ Non-significant, $\mathrm{STR}=\mathrm{ST}$ segment resolution at 60 minutes, TIMI= Thrombolysis in Myocardial Infarction., $\mathrm{MBG}=$ Myocardial blush grade, $\mathrm{EF}=$ Ejection fraction, $\mathrm{CK}-\mathrm{MB}=$ creatine kinase myocardial band, M-W test= Mann-Whitney U-test.

We had no reported cases with major adverse cardiovascular events (MACE) either in IC group or IV group during hospital stay and after 30 days. According to bleeding risk, there was higher incidence of TIMI minor bleeding in IV group 4 cases $(8 \%)$ than in IC group 3 cases $(6 \%)$, but statistically nonsignificant with $(\mathrm{P}$ value $=0.69)$. Patients randomized to IC Tirofiban compared with IV Tirofiban had statistically significant reduction in incidence of heart failure (Killip II or III) during hospital stay, 8 cases $(18 \%)$ in IC group vs 17 cases $(34 \%)$ in IV group with $\mathrm{P}$ value $=$ 0.03 , and also had a better ejection fraction after 30 days $(47.8 \pm 6.98) \%$ in IC group vs $(44.7 \pm 6.37) \%$ in IV group which was statistically significant with $\mathrm{P}$ value $=0.03$ and there was strong positive linear relationship between EF and infarct size (Table 4 and Fig 1).

Table (4): Clinical outcomes and secondary end points

\begin{tabular}{|c|c|c|c|c|}
\hline \multicolumn{2}{|c|}{$\begin{array}{ll}\text { Parameters } & \text { Groups }\end{array}$} & IC group $(n=50)$ & IV group $(\mathbf{n}=\mathbf{5 0})$ & $P$ value \\
\hline \multirow{3}{*}{$\sum_{\Sigma}^{5}$} & Death & 0 & 0 & \\
\hline & MI & 0 & 0 & \\
\hline & Stroke & 0 & 0 & \\
\hline \multicolumn{2}{|c|}{$\begin{array}{c}\text { Heart failure } \\
\text { (Killip II or III) }\end{array}$} & $8(16 \%)$ & $17(34 \%)$ & 0.03 \\
\hline \multirow{2}{*}{ : } & TIMI major & 0 & 0 & \\
\hline & TIMI minor & $3(6 \%)$ & $4(8 \%)$ & 0.69 \\
\hline \multicolumn{2}{|c|}{$\begin{array}{l}\text { Ejection fraction } \\
\text { (after } 30 \text { days) \% }\end{array}$} & $47.8+6.98$ & $44.7+6.37$ & 0.03 \\
\hline
\end{tabular}

IC group= Intracoronary group, IV group= Intravenous group, $\%=$ Percentage, $\mathrm{P}$ value=Probability value, $\mathrm{S}=$ significant, MACE $=$ Major adverse cardiovascular events, $\mathrm{MI}=$ myocardial infarction, TIMI $=$ Thrombolysis in Myocardial Infarction. 


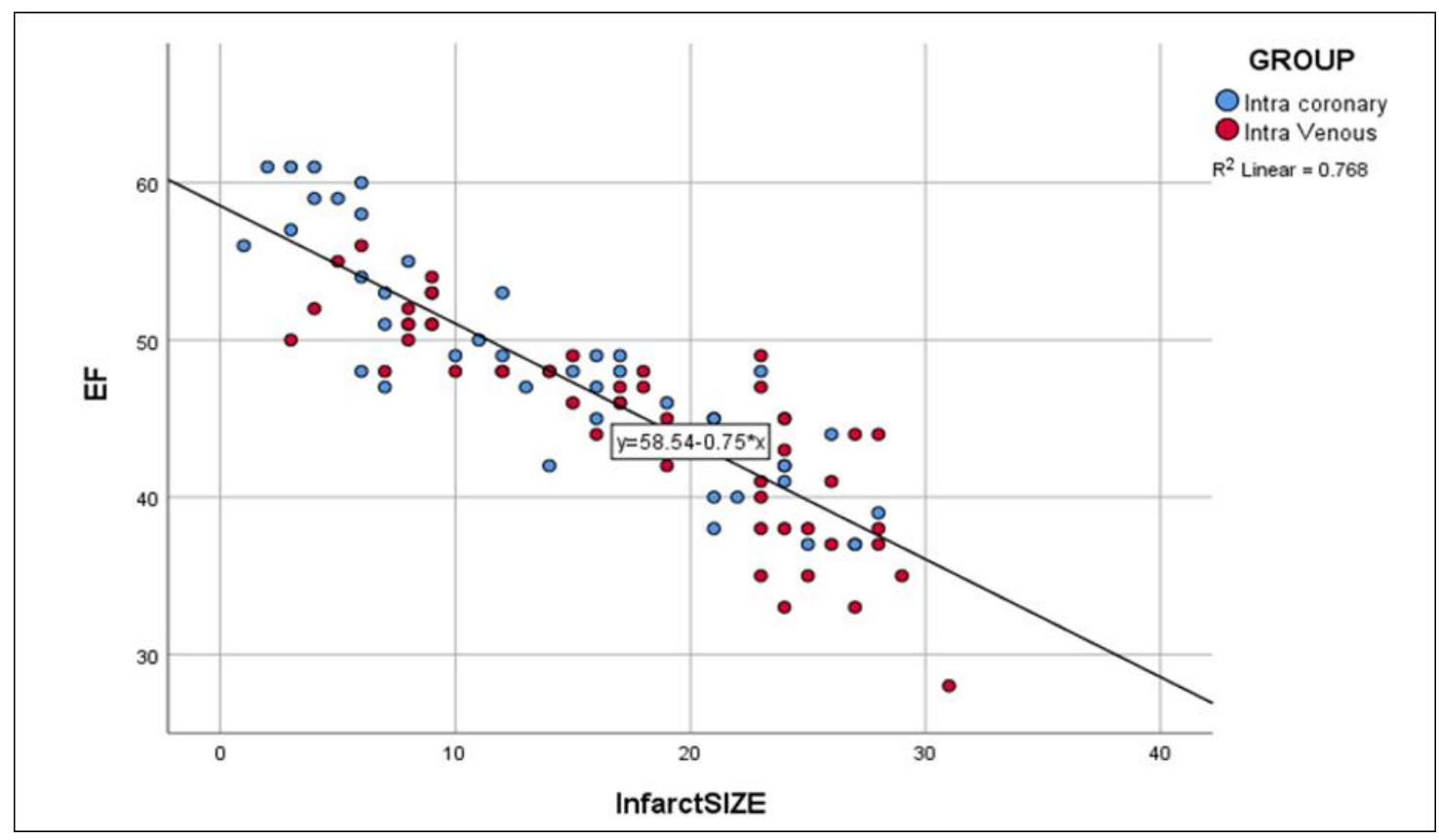

$\mathrm{EF}=$ Ejection fraction

Figure (1): Relation between left ventricular ejection fraction and infract size after 1 month from randomization

\section{DISCUSSION}

Despite the substantial progress that has been made in recent decades regarding the treatment of ACS, including thrombus aspiration and routine stenting, questions have been raised concerning the potential benefit of GPIs in ACS patients undergoing PCI. Positive benefits of tirofiban were observed in ACS patients undergoing PCI who received IC tirofiban compared with controls who received IV administration. These benefits included an increase in the incidence of complete perfusion and TIMI myocardial perfusion grade 3 after PCI and a reduction in MACE. The rationale for IC administration of tirofiban during PCI is to achieve a higher drug concentration in the area of the culprit lesion and in the distal bed of the culprit vessel. Compared with IV delivery of tirofiban, a higher drug concentration should result from IC delivery, leading to a greater procedural success rate (e.g., TIMI grade 3 flow) (Srinivasan and Prasad, 2011). The most important effect is that a high local concentration of GPI has a thrombolytic effect, which improves TIMI flow (Eitel et al., 2011). Therefore, it is logical to conclude that IC tirofiban yields better receptor occupancy and additional thrombolytic effects compared with IV administration.

Salvaging myocardium is the primary goal of reperfusion therapy, since infarct size correlates strongly with mortality after acute ST-segment elevation myocardial infarction. However, myocardial recovery after primary PCI is often suboptimal despite restoration of TIMI 3 flow, in part due to thrombus embolization which results in impaired 
micro-vascular perfusion and increased infarct size. Infarct size measured by cardiovascular magnetic resonance or tc99m sestamibi SPECT within 1 month after primary PCI is strongly associated with all-cause mortality and hospitalization for HF within 1 year. Infarct size may therefore be useful as an endpoint in clinical trials and as an important prognostic measure when caring for patients with STEMI (Stone et al., 2016).

Estimating infarct size after reperfusion therapy thus offers important prognostic utility. Laboratory measures of infarct size include biomarkers such as Creatine kinase (CK), creatine kinase myocardial band (CK-MB) and Troponin levels. While these tests are readily available and can be obtained in the acute setting, they are imprecise in comparison to infarct size assessed by cardiac imaging (Hartman et al., 2017). Myocardial Blush grade is an independent predictor for outcome in acute myocardial infarction patients treated with reperfusion therapy (Yusuf et al., 2018).

The present study was designed to maximize the likelihood that a reduction in infarct size could be demonstrated with intracoronary Tirofiban. One of the strongest baseline determinates of infarct size are anterior MI location (Stone et al., 2016), we therefore limited enrollment to patients with proximal or mid LAD occlusion (and without prior MI). We also restricted enrollment to patients who could be treated early, within six hours of maximum typical chest pain. Indeed, the median time from symptom onset to hospital arrival was 3 hours, and the median door to wire crossing time was
42.5 minutes. The study population thus represents a highly selected cohort of patients with large anterior MI (those with the greatest clinical need), in whom infarct size reduction should be feasible given early presentation and rapid treatment.

Our study aimed to clarify the effect of intracoronary versus intravenous injection of tirofiban on infarct size during primary PCI in patients with anterior STEMI. The study was carried out on 100 patients presented with anterior ST elevation myocardial infarction who underwent primary PCI, the cases were divided into 2 groups the first Intracoronary group that included 50 patients who were treated by intracoronary bolus infusion of tirofiban followed by IV maintenance dose infusion of tirofiban and the second Intravenous group that included 50 patients who were treated by intravenous bolus infusion of tirofiban followed by IV maintenance dose infusion of tirofiban, The two groups were matched regarding the age, gender, presence of coronary artery disease risk factors, hemodynamic data at time of presentation, onset of chest pain, time to wire crossing and number of stents inserted into lesion site.

Myocardial reperfusion was assessed by several complementary parameters, including post-PCI TIMI flow and STR, Infarct size was assessed 1 month after randomization by single photon emission computed tomography myocardial perfusion imaging (SPECT-MPI). There were a higher percentage of infarct size among IV group than in IC group, and the differences between both study groups was statistically significant. Our results were in agreement with those of previous 
two earlier randomized trials demonstrated infarct size reductions with intracoronary compared with intravenous glycoprotein $\mathrm{Ilb} / \mathrm{III}$ a receptor antagonist (despite enrollment of patients with nonanterior MI presenting up to 12 hours after symptoms) (Gu et al., 2010 and Thiele et al., 2012).

Our secondary endpoint was Major adverse cardiovascular events (MACE) (defined as cardiac death, stroke or reinfarction), heart failure (Killip II or III), bleeding and ejection fraction during hospital stay and after 30 days. We had no reported cases with major adverse cardiovascular events either in intracoronary group or intravenous group during hospital stay and at 30 days. There was an agreement with AIDA STEMI trial, who found nearly identical rates of MACE (and biomarker-assessed infarct size) with bolus intracoronary and intravenous abciximab (Thiele et al., 2012). However, a previous analysis found that treatment with IC administration of tirofiban was associated with significant benefits in terms of MACE compared with IV administration (Wang et al., 2012), but follow-up is required for longer periods.

All GPI may increase the risk of bleeding because of their antiplatelet activity and antithrombotic properties. Regarding safety end points, there were no differences between the two groups in the incidence of bleeding events. In patients with similar baseline characteristics who were randomized to an IC or IV group, the incidence of bleeding events was low, with no significant difference being noted between the two groups. There were no recorded cases with major bleeding and 4 cases presented with TIMI minor bleeding in intravenous group and 3 cases in intracoronary group which was statistically non-significant with. Despite of using heparin as a procedural anticoagulant, aspirin, clopidogrel and in addition to intravenous or intracoronary Tirofiban, bleeding events was low and this is not surprising because more caution is currently applied to the dosing of antiplatelet and antithrombotic agents, and closer attention is paid to the management of patients. We share the same results with $M a$ et al., (2020) which showed no significant differences in major bleeding or stroke incidences between the two groups.

Our study suggested that the concept of a direct link between infarct size and incidence of heart failure remains valid in modern STEMI patients treated by PPCI. the larger the infarct size, the higher the risk of developing adverse LV remodeling and experiencing heart failure, and our study concluded that there was extreme significant difference between patients with heart failure versus those without heart failure, regarding their defect size. Our results were in agreement with a result of prospective randomized trial of patients with STEMI undergoing primary percutaneous coronary intervention, intracoronary GPIIb/IIIa bolus administration in conjunction with unfractionated heparin, aspirin, and clopidogrel which showed no increase in free survival at 90 days compared with treatment by intravenous bolus application, despite a significant benefit in the occurrence of new congestive heart failure (Tang et al., 2015). 
Our study also showed improved myocardial reperfusion with IC GP $\mathrm{IIb} / \mathrm{III}$ inhibitors and less infarct size in patients undergoing primary PCI. This was in accordance with the observed improvement of LVEF in the IC group and share the same end results with a recent meta-analysis by (Elbadawi et al., 2017).

\section{CONCLUSION}

In patients with anterior STEMI presenting early after symptom onset, intracoronary tirofiban administration when compared to intravenous route during primary PCI resulted in infarction size reduction and lower heart failure incidence mainly driven by enhanced left ventricular systolic function however no distinction between two strategies on MACE or bleeding risk.

\section{REFERENCES}

1. Bernardo $C$, Sebik $R$ and Valgimigli $M$. (2014): The conundrum of antithrombotic drugs before, during and after primary PCI. Euro Intervention, 10: 64-73.

2. Casserly IP and David JM. (2010): Platelet glycoprotein IIb/IIIa receptor antagonists. Expert opinion on Pharmacotherapy, 1(3): 419-433.

3. Eitel I., Friedenberger, J., Fuernau, G., Dumjahn, A., Desch, S., Schuler and Thiele. (2011): Intracoronary versus intravenous bolus abciximab application in patients with ST-elevation myocardial infarction undergoing primary percutaneous coronary intervention: 6-month effects on infarct size and left ventricular function. The randomized Leipzig Immediate Percutaneous Coronary Intervention Abciximab i.v. versus i.c. in ST-Elevation Myocardial Infarction Trial (LIPSIAbciximab-STEMI). Clin Res Cardiol., 100: 425-432.

4. Elbadawi, A., Elgendy, I. Y., Mahmoud, K., Lenka, J., Olorunfemi, O., Reyes, A and Abbott. (2019): Metaanalysis of randomized trials of intracoronary versus intravenous glycoprotein IIb/IIIa inhibitors in patients with ST-elevation myocardial infarction undergoing primary percutaneous coronary intervention. Am J Cardiol., 120:1055-1061.

5. Gellatly, R. M., Connell, C., Tan, C., Andrianopoulos, N., Ajani, A. E., Clark, D. $\mathbf{J}$ and O'Brien. (2020): Trends of Use and Outcomes Associated With GlycoproteinIIb/IIIa Inhibitors in Patients With Acute Coronary Syndromes Undergoing Percutaneous Coronary Intervention. Annals of Pharmacotherapy, 54(5): 414-422.

6. Gu, Y. L., Kampinga, M. A., Wieringa, W. G., Fokkema, M. L., Nijsten, M. W., Hillege, H. L and Hoseyni Guyomi. (2010): Intracoronary versus intravenous administration of abciximab in patients with ST-segment elevation myocardial infarction undergoing primary percutaneous coronary intervention with thrombus aspiration: the comparison of intracoronary versus intravenous abciximab administration during emergency reperfusion of ST-segment elevation myocardial infarction (CICERO) trial. Circulation, 122:2709-17.

7. Hendriks, T., Hartman, M. H., Vlaar, P. J., Prakken, N. H., van der Ende, Y. M., Lexis, C. P and van der Harst. (2017): Contemporary value of peak CK-MB after STEMI in predicting infarct size, left ventricular ejection fraction, and mortality. The Burden of Myocardial Infarction, 40(5):322-328.

8. Ibanez B, James S, Agewall S, Antunes MJ, Bucciarelli-Ducci $C$ and Bueno $H$. (2018): 2017 ESC Guidelines for the management of acute myocardial infarction in patients presenting with ST-segment elevation: The Task Force for the management of acute myocardial infarction in patients presenting with ST-segment elevation of the European Society of Cardiology (ESC). European Heart Journal, 39(2): 119-177.

9. Levine GN, Bates ER, Blankenship JC, Bailey SR, Bittl JA and Cercek. (2016): ACC/AHA/SCAI focused update on primary 
percutaneous coronary intervention for patients with ST-elevation myocardial infarction: an update of the 2011 ACCF/AHA/SCAI guideline for percutaneous coronary intervention and the 2013 ACCF/AHA guideline for the management of ST-elevation myocardial infarction. Journal of the American College of Cardiology, 67(10): 1235-1250.

10. Ma Q, Ma Y, Wang X, Li S, Yu T and Liu W. (2020): Intracoronary compared with intravenous bolus tirofiban on the microvascular obstruction in patients with STEMI undergoing PCI: a cardiac MR study." The International Journal of Cardiovascular Imaging, 36: 1-12.

11. Marco V and Tebaldi M. (2010): Safety evaluation of tirofiban. Expert Opinion on Drug Safety, 9(5): 801-819.

12. Maznyczka AM, Oldroyd KG, McCartney P, McEntegart $M$ and Berry C. (2019): The potential use of the index of microcirculatory resistance to guide stratification of patients for adjunctive therapy in acute myocardial infarction. JACC: Cardiovascular Interventions, 12(10): 951-966.

13. Srinivasan $M$ and Prasad A. (2011): Adjunctive intracoronary antithrombotic therapy: time to revisit an old strategy? J Invasive Cardiol., 21: 224-228.

14. Stone GW, Selker HP, Thiele H, Patel MR, Udelson JE and Bagnall. (2016): Relationship between infarct size and outcomes following primary PCI: patientlevel analysis from 10 randomized trials." Journal of the American College of Cardiology, 67(14): 1674-1683.

15. Tang, X., Li, R., Jing, Q., Liu, Y., and Liu. (2015): Efficacy and safety of intracoronary versus intravenous administration of tirofiban during percutaneous coronary intervention for acute coronary syndrome: a meta-analysis of randomized controlled trials. PloS one, 10:6.
16. Thiele $H$, Schindler $K$, Friedenberger $J$, Eitel I, Fürnau G, Scholz and Adam. (2012): Intracoronary compared with intravenous bolus abciximab application in patients with ST-elevation myocardial infarction undergoing primary percutaneous coronary intervention: the randomized Leipzig immediate percutaneous coronary intervention abciximab IV versus IC in STelevation myocardial infarction trial. Circulation, 118:49-57.

17. Thiele H, Wöhrle J, Hambrecht R, Rittger $H$, Birkemeyer $\mathbf{R}$ and Kerber. (2012): Intracoronary versus intravenous bolus abciximab during primary percutaneous coronary intervention in patients with acute ST-elevation myocardial infarction: a randomised trial. Lancet, 379:923-931.

18. Wang Y, Wu B and Shu $X$ (2012): Metaanalysis of randomized controlled trials comparing intracoronary and intravenous administration of glycoprotein IIb/IIIa inhibitors in patients with ST-elevation myocardial infarction. Am J Cardiol., 109: 1124-1130.

19. Wilmer CI (2018): Intracoronary high-dose bolus tirofiban administration during complex coronary interventions: A United States-based case series. Cardiovascular Revascularization Medicine, 19(1): 112-116.

20. Yusuf J, Das D, Mukhopadhyay $S$ and Tyagi (2018): Correlation of QRS duration with myocardial blush grade as a marker of myocardial reperfusion in primary percutaneous coronary intervention. Indian Heart Journal, 70: 359-364.

21. Zeymer U, van't Hof A, Adgey J, Nibbe L, Clemmensen and Cavallini. (2014): Bivalirudin is superior to heparins alone with bailout GP IIb/IIIa inhibitors in patients with ST-segment elevation myocardial infarction transported emergently for primary percutaneous coronary intervention: a prespecified analysis from the EUROMAX trial. European Heart Journal, 35(36): 2460-2467. 
مقارنة بين حقن التيروفيبان داخل الثريان التاجي مقابل الحقن التهابن

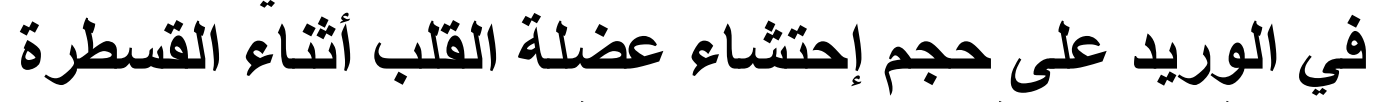

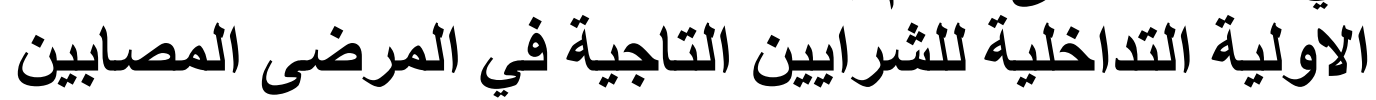

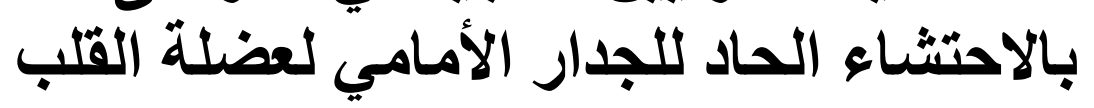

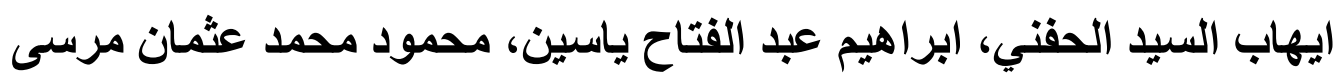

قسم أمراض القلب والأوعية الدموية، كلية الطب، جامعة الأزهر

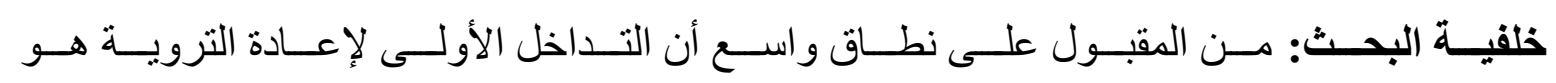

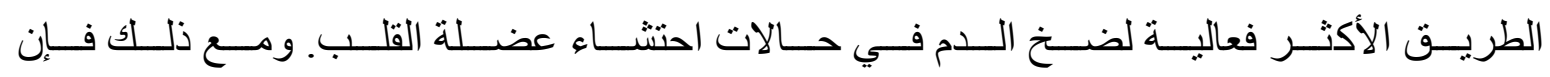

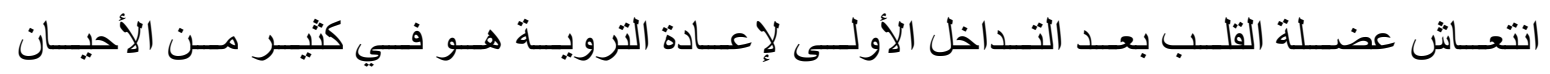

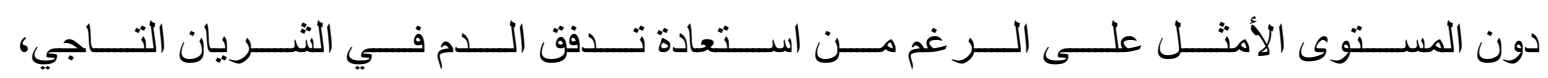

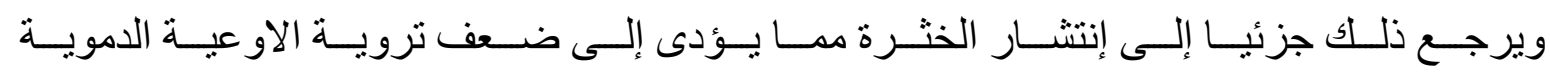

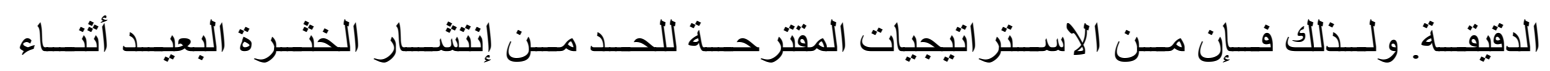

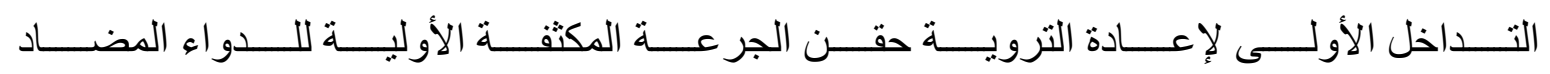

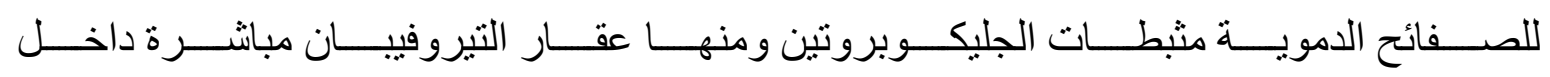
الثريان التاجي.

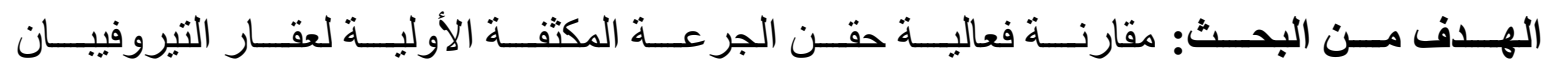

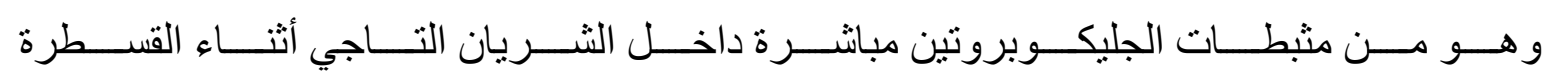

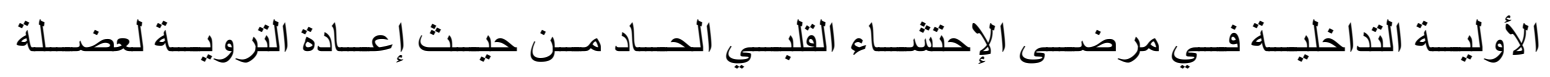
القلب.

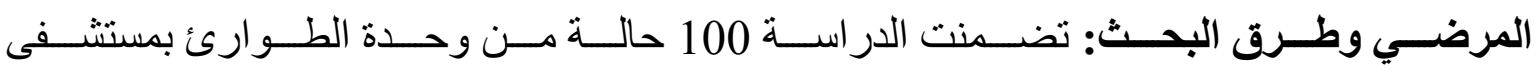

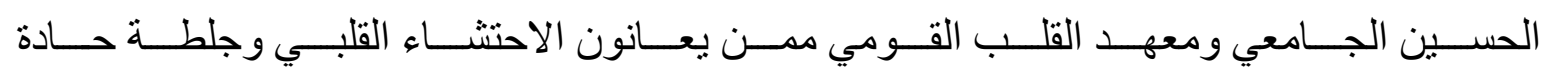

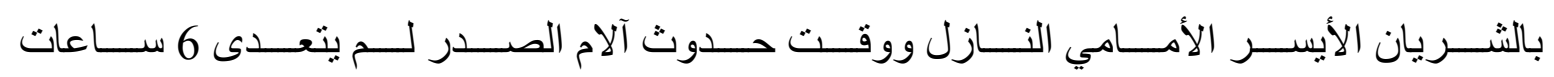

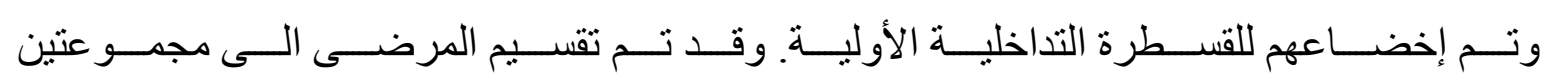

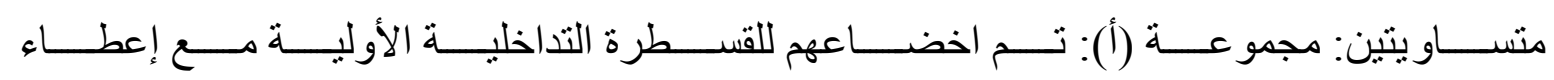

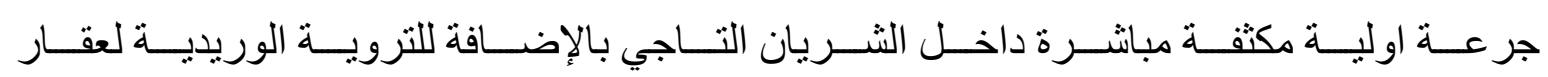




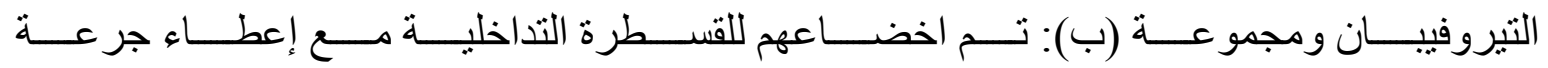
أولية مكثفة في الوريد بالإضافة للتروية الوريدية لعقار التيروفيبان.

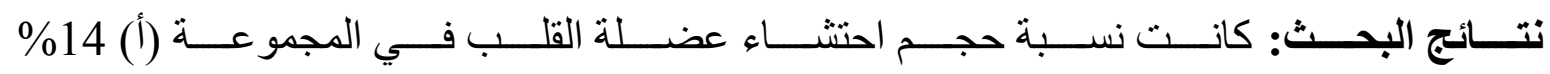

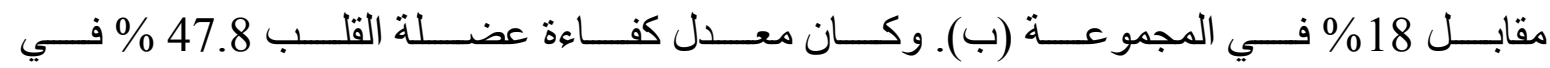

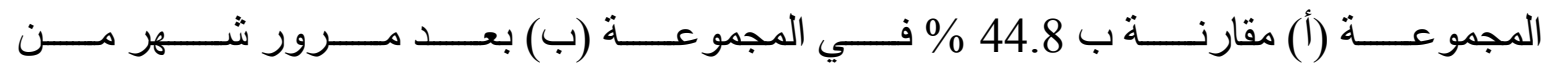

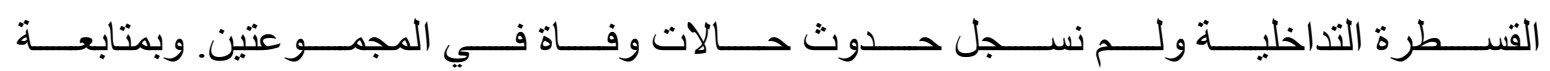

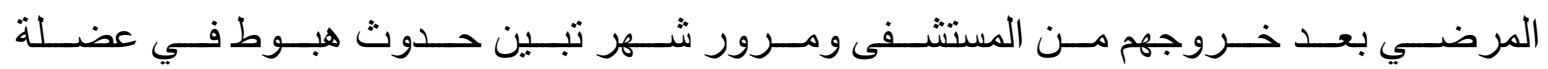
القلب بنسبة 16\% في المجموعة (أ) مقابل 34\% في المجمو عة (ب).

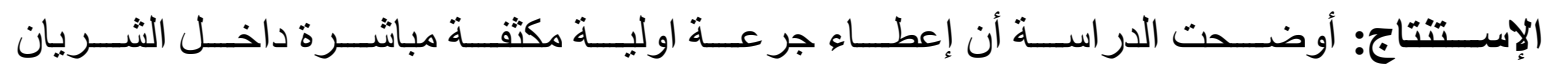

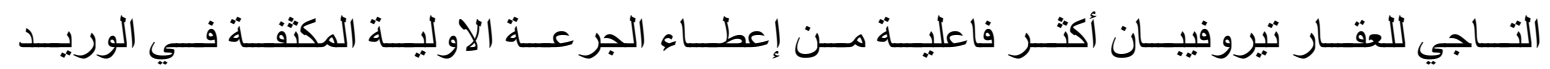
و أقل في حجم احتشاء عضلة القلب وفي نسبة حدوث هبوط في عضلة القلب. 